\title{
Construction of E-government System Framework Based on the Information Resource Sharing
}

\author{
Ying Lu \\ School of Computer and Information Engineering \\ Harbin University of Commerce \\ Harbin, China \\ 11978y@hrbcu.edu.cn
}

\begin{abstract}
Due to the implementation of information technology and the various e-government new businesses, egovernment system has generated a lot of valuable information resources as well as a large amount of redundant information. Information sharing can save the cost of information collection, and the collected information can be used by many a government agency. Based on the sharing of information resources, an e-government system framework is design in the paper at three levels, namely, network infrastructure, information resources, and data exchange platform.
\end{abstract}

Keywords-E-government;information resources; Information sharing; system framework

\section{INTRODUCTION}

The E-government has a variety of titles in the world, such as e-government, digital government, network government, and information-based government. Among five application fields of information superhighway that all countries in the world actively advocate, the e-government comes in first. Government informatization is the premise of economy and society informatization, and the e-government is an important symbol of government informatization[1].The government information is stored on the readable media of a computer in the form of digital code and can be exchanged and transmitted on the Internet in the process of carrying out e-government. It is one of egovernment information resources, E-government information is widespread in governments at all levels, If there is no unified management, the various components of e-government system that has been built can hardly communicate with each other well, which is surely against the effective use of information[2]. In this paper the practical significance of sharing information resources in the egovernment system is analyzed. In addition, the egovernment system framework on the basis of sharing information resources is design based on the principles of planning in advance, the easier issues first, and combination of centralization and distribution.

Government agencies vary a lot, and government functions are all-inclusive. The government structure determines the complexity of its operation process[3].Taking the opportunity of sharing e-government information resources, the author re-examines and re-designs the process of government administration. It enables a government agency not to run alone but in an optimized overall process, so as to improve government efficiency [4].

Information is valuable in the social and economic life. It can bring economic benefits to the owners and users of information[5]. The higher the degree of information sharing is, the more the value that it embodies. However, because the overall interests of the country are not always consistent with the partial interests of government agencies, the information may not be effectively used and thus information resources may be wasted $[6]$. The governments of many countries have established websites on the Internet to announce its duties and functions and to carry out network examination and approval and other administrative work. As a result, the information resources in the e-government system can be shared, the administrative efficiency can be enhanced, and public supervision over the government can be facilitated[7].

\section{BASIS OF CONSTRUCTING E-GOVERNMENT SYSTEM} FRAMEWORK

\section{A. Planning in Advance}

Sort out the business processes between different departments as well as the upper and lower authorities, and make comprehensively a plan about collection, processing, transmission, and use of information. On the basis of planning, analyze the data flow and re-build the data structure; migrate the accumulated database resources to a new database[8]. A program for data input at the initial stage of its development and application should be made so as to load the entire batch of data into the new database. In this way, the information resources can form a system in order to avoid decentralization.

\section{B. Easy Issues Firs}

Currently, the construction of e-government relies mainly on the government's investment. After all, the government funding is limited and a single mode of operation has resulted in the financial strain. In addition, constrained by the level of management, the e-government systems of many local governments can not be operated systematically, so that it affects the development of e-government. So, the author selects the needed-urgently system in the system framework design in the principle of "easy issues first" [9]. 


\section{Combination of Concentration and Distribution}

Resource sharing does not mean to gather all the data together and to be managed by one department, because the centralized management of data can hardly fit into the real condition of departments using such information resources[10]. The cost of centralized management of data is high, and the high risk of centralized management of data results in the fact that a lot of confidential information can not be centrally managed. The ideal solution for building egovernment system based on information resource sharing is to combine centralization and distribution. Specifically, demographic information, legal person information, information on space and natural resources, macroeconomic and social development information and other basic information, all should be centrally managed by the Information Center, while other information should be managed by different departments themselves.

\section{DESIGN OF E-GOVERNMENT SYSTEM FRAMEWORK}

\section{BASED ON THE SHARING OF INFORMATION RESOURCES}

The e-government system framework based on the sharing of information resources rests a lot with network construction, and focuses on the integration of resources and the construction of a unified government platform. Through the sharing of information resources, the process of government administration can be optimized, the work efficiency of government departments can be improved, and public satisfaction can be increased. Figure 1 shows the egovernment system framework based on the sharing of information resources.

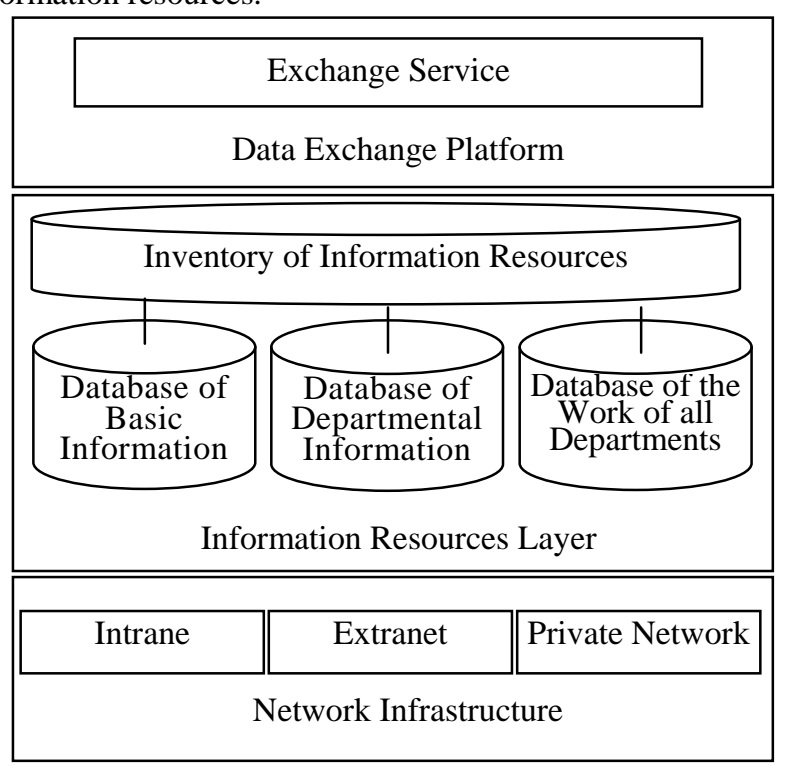

Figure 1. E-government system framework

\section{A. Network Infrastructure}

The information processing rests on the network in the implementation process of e-government. The network for egovernment can be divided into three parts: intranet, extranet, and private network.
The Intranet refers to government agencies' business network serving the daily e-office of government agencies. Such e-office includes document handling, examination and approval, and other business processing activities. It is mainly to deal with classified information.

The private network refers to the network for the exchange of information resources between government departments. According to agency functions, such agencies are conditionally connected through private network within the scope of business. On the basis of this private network, a paperless office platform and a mechanism for information collection and feedback are built. Thus, the various government departments can share the information resources and improve the efficiency of government administration.

The extranet refers to government's public information network relying on the Internet. It serves the public and enterprises by providing online services and disseminating government information; in addition, it is also a channel for the information exchange between government and between various departments at all levels.

Government's intranet and private network both are mainly used to transmit classified government information. So, to ensure the security of core secrets, intranet and private network must be physically isolated from the extranet. All applications that are related to public service should fall under extranet. Thus, the application of extranet intends to expand and that of intranet to shrink.

\section{B. Information Resources Layer}

The further and comprehensive development of egovernment depends on the integration and sharing of information resources in public services, market regulation, and decision support. The purpose for sharing is to make full use of information resources. Sharing of information resources can proceed from the following four aspects.

\section{1) Construct Basic Information Database}

Include the construction of Basic Database on Population, Basic Database on Legal Person Information, Basic Database on Space and Natural Resources, and Basic Database on Macro-Economic and Social Development. The Basic Database on Population is an information system that is based on demographic information; it takes citizen's ID number as the only mark and records the change of basic information and social pathway of citizens. The Basic Database on Legal Person Information is a standardized system dealing with the collection, processing, update, exchange, and service of basic information of legal entities. The Basic Database on Space and Natural Resources is a logical basic information library that contains the information of physical and geo-spatial distribution of natural resources. The Basic Database on Macro-Economic and Social Development covers the management, development and utilization of national macro basic information resources including national economy, social development, science and technology, education, and environmental resources.

2) Construct Information Resources Library of Government Departments 
The information system of government departments is divided into three categories: the first category includes the system of office business resources and the system of macroeconomic management which plays a central role in strengthening supervision, improving efficiency and promoting public service. The second category includes the business system for enhancing government revenue and ensuring the reasonableness of public spending. The third category consists of the business system for safeguarding the social order and laying a solid foundation for the construction of economic and social development. It should strengthen the construction of critical business systems, improve the system of office business resources, and promote business collaboration and resources integration. The construction of business systems should be unified and promoted by stages.

3) Compile the Business Database of Various Departments

With the development of e-government, the various departments have accumulated a considerable business data which, however, were generated and managed through isolated application systems. So, the scope of services of these dada are limited within its very department, which results in the facts that the dada of different databases are overlapped, a large quantity of data are repeatedly collected, and there are more and more application systems. The problem can be solved through the following several steps: first, sorting out the data; the second, classifying the dada in accordance with the way of dada production, i.e. collected data, process data, and comprehensive statistical data, and comprehensively review the business information of various departments; the third, compile the information resources according to the hierarchical level of information resources from major categories to single items, and business database to data items.

\section{4) Establish Directory of Information Resources}

Applying directory management mode to all kinds of information resources is propitious to the various departments comprehensively understanding and using global information resources. The directory is mainly used to manage two types of resources: information resources and service resources. Here, the service resources refer to some application modules that can be reused for certain function. A large number of such functional modules that are distributed in known locations are packaged as service resources. The service resources are classified and managed through directory and are available to the public to share, so as to reduce efforts of duplicated development. The Directory of e-government information resources should be managed and stored in distributing method. The overall directory of government information resources should be stored and provided on government extranet platform, while the sub directory of relevant resources should be stored in industrial or local departments. The overall directory and the sub directory should be of time synchronization, and navigation services based on the overall directory should be provided.

\section{Data Sharing and Exchange Platform}

Exchanging information between the various departments and systems is a guarantee to achieve information resource sharing. The e-government system requires data exchange capability; many systems use nodeto-node exchange method, which requires that each system should have a dedicated data exchange subsystem to fit into its specific situation. As shown in Figure 2, two application systems need two interfaces to achieve information exchange.

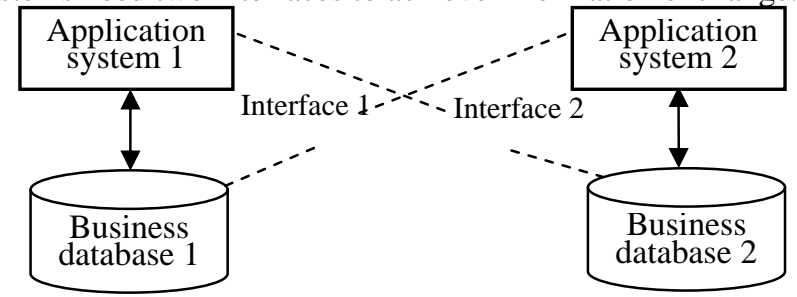

Figure 2. The node-to-node exchange of two application systems

If there are only a small number of application systems, the dedicated node-to-node data exchange between application systems can meet the needs. With extension of e-government, there are more and more application systems, a growing number of departments can participate in the exchange, and the number of interfaces increases following the rule of $n(n-1)$. For example, if there are seven application systems, and if the traditional node-to-node exchange method is adopted, 42 interfaces are needed.This is not only complex and difficult to maintain them, but also is of high cost. However, if data sharing and exchange platform are adopted, seven application systems only need 14 interfaces, which have unified interface standard; to complete the exchange between different nodes, appropriate configuration should ensure reliable, safe and efficient data exchange. Figure 3 illustrates the data exchange based on data sharing and exchange platform.

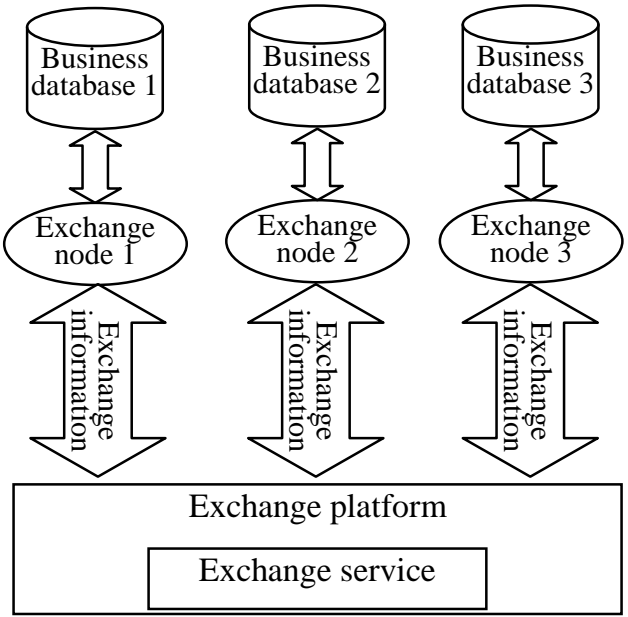

Figure 3. Data exchange based on data sharing and exchange platform

Technically, the sharing and exchange platform of information resources is built based on the middleware. This 
can ensure the progressiveness and reliability of the platform. The data sharing and exchange platform brings together the population information, legal person information, space information, macro-economy information and other basic information resources of the government. Moreover, the platform can provided various government departments with shared services, and provides interface and management services for certain government department visiting the information resources of its superior department, subordinate department, or equative other departments. Thus, the crosssystem, cross-application, cross-regional interoperability and sharing of information resources of e-government system can be realized, and the data sharing and exchange platform can support the document exchange between government departments and the parallel examination and approval as well.

\section{CONCLUSION}

The E-government information is the government information in the field of e-government. It has both the characteristics of government information and electronic characteristics, which should be taken into consideration when sharing such information. In this paper, we have established an e-government system framework on the basis of network construction, resources integration, and unified data exchange and sharing platform. The system framework has integrated all aspects of information involved in the egovernment business and decision-making activities of government departments. It contains four basic resources databases, the information resources of the various functional systems, the business resources of various government departments, and the many other aspects of government and social resources. A preliminary design has been done in this paper, and it is necessary to do a furhter study on it in the future to make it more practical.

\section{REFERENCES}

[1] Mohammad Alomari, Peter Woods, Kuldeep Sandhu, Predictors for e-government adoption in Jordan: Deployment of an empirical evaluation based on a citizen-centric approach, Information Technology \& People, vol. 25(2), pp.207-234, 2012

[2] Marije L. Teerling, Willem Pieterson, How to improve e-government use: An empirical examination of multichannel marketing instruments, Information Polity, vol. 16(2), pp.171-187, 2011

[3] ChristopherG. Reddick, HishamM. E. Abdelsalam, HatemA. Elkadi, Channel choice and the digital divide in e-government: the case of Egypt, Information Technology for Development, vol.18(3), pp.226246, 2012

[4] Nalini Kotamraju, Thea van der Geest, The tension between usercentred design and e-government services, Behaviour \& Information Technology, vol. 31(3), pp.261-273, 2012

[5] Wallace J Taylor, Stewart Marshall, Shahram Amiri, The evolution of the i-society in the delivery of e-government, AI \& SOCIETY, vol. 3, pp.359-368, 2008

[6] Göran Goldkuhl, Generic regulation model: the evolution of a practical theory for e-government, Transforming Government: People, Process and Policy, vol. 5(3), pp.249-267, 2011

[7] TonyE. Wohlers, Lynne Bernier, Innovative City Hall: A Comparative Case Study of Policy Adoption in the U.S. and France, Journal of Information Technology \& Politics, vol. 9(4), pp.415-432, 2012

[8] ShahjahanH. Bhuiyan, Trajectories of E-Government Implementation for Public Sector Service Delivery in Kazakhstan, International Journal of Public Administration, vol. 34(9), pp.604-615, 2011

[9] N Mlika-Cabanne,R Harbour,HdeBeer,M Laurence, R Cook,S Twaddle,Sharing hard labour: developing a standard template for data summaries in guideline development,Quality and Safety in Health Care(BMJ Available online 2011), vol. 20(2), pp. 141-145, 2011

[10] Tianxi Dong, Zheng Qin, Nan Lin, Daifeng Li, A New Framework for Designing E-Government Procurement in China Based on Ontology and Business Component , Journal of Service Science and Management, vol. 3(3), pp.298-308, 2010 